\title{
Endoscopic use of cyanoacrylate glue in the treatment of urethral fistula
}

André Ramos Sorgi Macedo, Silvio Henrique Maia de Almeida, Marco Aurélio de Freitas Rodrigues, Luís Gustavo Toledo, Rafael Agostinho Maioli

Department of Surgery, Division of Urology, State University of Londrina, Londrina, PR, Brazil

Purpose: The aim of this video is to demonstrate an endoscopic and minimally invasive repair of an urethrocutaneous fistula with cyanoacrylate glue.

Materials and Methods: A 56 year-old-man with post-infectious urethral stricture and recurrent perineal abscess formation due to urethral fistulas.

Results: The operative time was 60 minutes, no major complications were observed perioperatively and postoperatively. At a follow-up time of 6 months the patient had no evidence of recurrent fistula and abscess formation.

Conclusions: The endoscopic use of cyanoacrylate glue represents a safe and minimally invasive approach that might be offered as a first line option for the treatment of urinary fistulas in selected patients, especially those with narrow and long tracts.

\section{ARTICLE INFO}

Available at: www.brazjurol.com.br/videos/july_august_2013/Macedo_602_603video.htm

Int Braz J Urol. 2013; 39 (Video \#9): 602-3

Submitted for publication:

January 29, 2013

Correspondence address:

Dr. André Ramos Sorgi Macedo

Accepted after revision:

Abril 25, 2013

Rua Jau, 343 Londrina, PR, Brazil

Telephone: +55 43 9905-6832

E-mail: andre_macedo9@yahoo.com.br 


\section{EDITORIAL COMMENT}

The video nicely depicts a minimally invasive technique which may be helpful in select cases of urethral stricture. In this case the urethral tracts were long and of fairly small caliber. Cyanoacrylates are monomers that polymerize quickly when hydrogen ions are present, creating an acrylic resin, which solidifies quickly. They exist in two forms: short-chain cyanoacrylates (methyl-2 orethyl-2) that are rarely used, because of rapid degradation into the toxic breakdown products of cyanoacrylate and formaldehyde and the long-chain cyanoacrylates (n-butyl-2-cyanoacrylate andn-octyl-

\section{REFERENCES}

1. Sinha S, Naik M, Wright V, Timmons J, Campbell AC: A single blind, prospective, randomized trial comparing n-butyl 2-cyanoacrylate tissue adhesive (Indermil) and sutures for skin closure in hand surgery. J Hand Surg Br. 2001; 26: 2645.

2. Hosseini SM, Rasekhi AR, Zarenezhad M, Hedjazi A: Cyanoacrylate glue dressing for hypospadias surgery. N Am J Med Sci. 2012; 4: 320-2.

3. Prestipino M, Bertozzi M, Nardi N, Appignani A: Outpatient department repair of urethrocutaneous fistulae using n-butyl-cyanoacrylate (NBCA): a single-centre experience. BJU Int. 2011; 108: 1514-7. 2-cyanoacrylate) that degrade more slowly, with minimal toxic buildup (1). As a result, the longchain cyanoacrylates are safe and are commonly used for skin closure in both urologic and nonurologic surgeries (2). The use of long-chain cyanoacrylates does not seem to compromise subsequent surgeries should they become necessary (3). Care must be taken not to leave behind excess material in bladder as there is a risk for stone formation. A recent report describes use of N-butyl-2-cyanoacrylate followed by fibrin glue for the treatment of post- prostatectomy vesicourethral anastomotic leaks (4). In their series of ten patients they covered the cyanoacrylate with a layer of fibrin glue and achieved good results.

4. Lim JH, You D, Jeong IG, Park HK, Ahn H, Kim CS: Cystoscopic injection of N-butyl-2-cyanoacrylate followed by fibrin glue for the treatment of persistent or massive vesicourethral anastomotic urine leak after radical prostatectomy. Int J Urol. 2013: 6; [Epub ahead of print].

Dr. Hubert Swana

Pediatric Urology Nemours Children's Hospital Orlando Orlando, FL, USA

E-mail: hswana@nemours.org 